\section{William Haseltine}

Can developing countries benefit from drugs that are tested in their territory by virtual company outsourcing? Haseltine's recent experiences in India make him believe it is possible.

During the 13 years that he was CEO of Human Genome Sciences (HGS), William Haseltine rarely traveled for pleasure. He was even less mobile before his tenure at the Rockville, Maryland-based genomics firm that he founded in 1992; as a cancer and AIDS researcher at the Dana Farber Cancer Institute, he scarcely found the time to take a long lunch break.

So, last January, a few weeks after resigning from HGS as the focal point of a sweeping new reorganization, Haseltine went to India to relax and then survey the country's much discussed research and development infrastructure and talent pool. The experience moved him. You might even say he came back with a new mantra. Today, with the benefit of hindsight-and several more trips to India, and then China and Eastern Europe-Haseltine says he has formulated a vision for the future of drug development.

"The old model for drug development doesn't work anymore," he says. "The sad thing is that it's mostly those outside biotech and pharma that realize that this model is broken. What we need is a whole new way of approaching R\&D." Certainly, the model Haseltine implemented at HGS has not yet proved commercially successful; in 13 years at the helm, he did not put a single product on the market.

But Haseltine is looking forward rather than to the past. His vision is of a network of virtual companies in the United States managing every single step of drug development, ranging from discovery and development, to manufacturing, from the bottom up. For example, he envisions hiring out discovery researchers in, say, China, clinical trial clinicians in India and perhaps manufacturing experts in places like Poland.

The idea of a virtual biotech is not new, but there is renewed interest lately because of these firms' cheap labor costs, low burn rates, outsourcing expertise and low infrastructure requirements. Indeed, at BIO's annual meeting in Philadelphia in June, a panel moderated by Hal Broderson, a managing director of Rock Hill Ventures in West Conshohocken, Pennsylvania, concluded that the time for the virtual biotech has come, partly on the basis of a nine-year analysis of data from this type of company.

Of course, Haseltine will need a highly experienced team at headquarters to pull it off. Even so, Raj Bawa of Bawa Consulting in Fairfax, Virginia, a company helping clients develop medicines in India and Asia, says the list of things that can go wrong with outsourcing is long, even for those with experience. "It takes a lot of time, money, and one-on-one contact-on a very regular basis-with the team [abroad] before you start achieving all of those hoped-for efficiencies," he says.

For Haseltine's purposes, these regions also represent the chance for making medicines with researchers and companies accustomed to doing more with less. But rather than merely developing them in these places, Haseltine aims to introduce the finished products there first.

His idea certainly makes a lot of political and clinical sense. Western drug companies that conduct clinical trials in places like India, Africa and southeast Asia, rarely launch the products that come from these trials in these countries. It is that point, after all, that fuels complaints from antiglobalization activists who claim Western drug companies are exploiting developing nations (Nat. Biotechnol. 22, 1194-1194,
2004). "It only takes one person who doesn't like what an American company is doing in a developing country to destroy the best-laid plans," comments Victoria Hale, founder of nonprofit Institute for OneWorld Health.

Hale also cautions that many more things can still go wrong with Haseltine's vision. She says there's a big difference between a virtual company and a few guys with business cards. It takes a critical mass of talent to manage every phase of the venture. Building the business is not going to be difficult for him; executing on the strategy is going to be the challenge.

David Agus, an oncologist at the Cedars Sinai Cancer Research in Los Angeles, California, who joined Haseltine on a recent trip to India, recognizes the value of the new venture: "By working with countries like India, Bill is going to prove that drugs can be developed in 'quick time,' for an order of magnitude less money than what it takes today."

Also, introducing the drug in developing countries gives the US Food and Drug Administration and European Medicines Agency (EMEA) the benefit of at least some preliminary phase IV data on patient subpopulations. And, according to Haseltine, "We can use data collected from the markets there to enhance our filings in America and Europe, which should shorten the review process" (Nat. Biotechnol. 23, 765, 2005).

Today, with the benefit of
hindsight-and several
more trips to India, and
then China and Eastern
Europe-Haseltine says
he has formulated a
vision for the future of
drug development

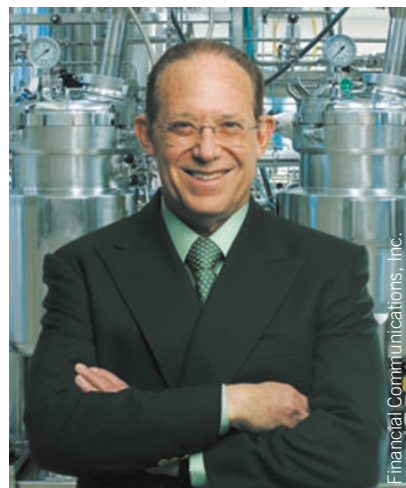

Ascher Shmulewitz, CEO of Medgenesis Partners of Glil Yam, Israel, a serial entrepreneur and veteran of the pharmaceutical and medtech fields, says Haseltine is spot on with his strategy of fusing a virtual company with bottom-to-top drug development outsourcing. "We're long overdue for a new model for developing drugs using the skills of companies in places like India and Latvia, for example," he says. "These companies have been making generics for years. Let me tell you, nothing forces you to be more efficient than making low-margin generics." It remains to be seen whether they can innovate (Nat. Biotechnol. 23, 11, 2005).

Haseltine would not say when he plans to launch his virtual company. Nor would he say what diseases he aims to target first, except to say, not surprisingly, that "cancer, HIV-AIDS, and infectious diseases" are probably the most logical place for him to start. He says he will make necessary announcements in due course, vowing to take his time and get every last detail put in place.

Details will be important. Haseltine's credentials as a genomics visionary are undisputed; it's delivering on a strategy that so far has eluded him.

Stephan Herrera, New York 